\title{
Concern About Contracting COVID-19 Predicts Men's Preference for Female Facial Femininity, But Not Women's Preference for Male Facial Masculinity
}

\author{
Farid Pazhoohi ${ }^{1} \cdot$ Sepide Pazhouhi ${ }^{2} \cdot$ Alan Kingstone $^{1}$ \\ Received: 11 October 2020 / Revised: 28 November 2020 / Accepted: 30 November 2020 / \\ Published online: 6 January 2021 \\ (C) The Author(s), under exclusive licence to Springer Nature Switzerland AG part of Springer Nature 2021
}

\begin{abstract}
Objectives Humans have evolved a behavioral system that responds to perceptual cues suggesting the existence of a pathogenic threat in other individuals and the environment. While previous investigations have reported that individuals' sexual preferences are influenced by a pathogen threat, the empirical support for face preference is mixed (i.e., the association of pathogenic threat and individuals' preferences for masculine and/or feminine faces is equivocal). The COVID-19 pandemic provides the opportunity to investigate the association of pathogenic threat and men's and women's preferences for sexual dimorphism of faces in the opposite sex in a real-world pathogenic situation. Methods Data were collected during COVID-19 pandemic (March 2020) from men and women in the United States, and women in Iran, on preferences for masculinity in men's faces using women participants, and femininity in women's faces using men. Results Results showed that concern about an actual pathogenic threat (i.e., contracting COVID-19) predicts men's preference for female facial femininity, but not women's preference for male facial masculinity (for both U.S. and Iranian women).

Conclusion By using an actual pathogenic threat, our results support previous findings that men's preferences for female faces are shifted to less feminine faces under pathogenic threat. Moreover, our results provide support for the distinction between the behavioral immune system and pathogen disgust, at least for men's preference for feminine female faces.
\end{abstract}

Keywords Pathogen threat - Sexual dimorphism · Femininity and masculinity $\cdot$ COVID-19 pandemic

Farid Pazhoohi

pazhoohi@gmail.com

Extended author information available on the last page of the article 
As an adaptation to resist environmental pathogens causing infectious diseases, in addition to immunological responses, humans and other animals have evolved a behavioral immune system that endows them with behavioral responses to perceptual cues suggesting the existence of a pathogenic threat in other individuals and the environment (Schaller 2011). In the case of humans, such adaptation has shaped human social cognition and behavior to identify and avoid pathogenic stimuli (Schaller 2011). One such adaptation is choosing and preferring mates resistant to parasites, as they produce genetically resistant offspring and provide better parental care (Hamilton and Zuk 1982; Thornhill and Gangestad 1993). As a result, regional variation in pathogenic stress influences mate preferences and behaviors across cultures and regions (Gangestad and Buss 1993; Low 1990; Tybur and Gangestad 2011). Sexually dimorphic features, as indicators of parasite resistance and genetic fitness in a potential mate (Puts et al. 2012; Thornhill and Gangestad 1999), act as cues for mate choice and preference in potential partners (Barber 1995; Rhodes et al. 2005). Choosing a masculine male partner may confer potentially heritable health benefits to women where pathogenic loads and disease risks are high, thereby influencing women's sexual strategy and preference for more masculine men (DeBruine et al. 2010a; Gangestad and Buss 1993; Puts et al. 2012). Perception of masculinity in male faces is associated with their actual health and immune system (Rhodes et al. 2005). Similarly, men may benefit from choosing a feminine female partner where there is higher pathogenic prevalence, as such women are potentially more pathogen resistant and healthier (Gangestad and Buss 1993). On other hand, cross-cultural data suggest that men prefer less feminine partners in harsher environments, possibly because less feminine features indicate higher abilities in resource acquisition and holding, which might be more important than fecundity in demanding environments (Marcinkowska et al. 2014)

Building on the assumption that masculinity in male faces signals good health and is associated with strong resistance to parasites and disease (Rhodes et al. 2003), previous research has associated preference for masculine male faces with pathogen prevalence. For example, in a cross-cultural study, it was shown that women's preference for masculinity in men's faces was predicted by national health index, including mortality rates, life expectancies, and the impact of communicable diseases (DeBruine et al. 2010a). Moreover, presumably due to higher parasite load, Jamaican women preferred more masculine male faces than their British counterparts (Penton-Voak et al. 2004). Further cross-cultural research supports the association between preference for cues to testosterone in male faces and societal-level measures of parasite stress (Moore et al. 2013). However, it should be noted that not all studies support the association between masculinity in male faces and disease resistance (Scott et al. 2010). Dixson et al. (2017) using participants from Vanuatu in the South West Pacific did not find a relationship between pathogen exposure and preference for masculine male faces. Similarly, exposure to pathogens in an experimental study did not support women's preference for masculine male faces (McIntosh et al. 2017). And contrary to the argument that women prefer masculinity under poor health conditions (DeBruine et al. 2010a), Marcinkowska et al. (2019) in a cross-cultural study reported that women had a greater preference for masculine faces in favorable conditions where offspring survival is higher. Support for this latter finding has recently been provided by Pereira and colleagues (2020).

Equivocal findings are also apparent from similar studies testing the relationship between men's preferences for feminine female faces and pathogen prevalence. For 
example, in a cross-cultural study, men's preference for female facial femininity correlated positively with the health of the nations, indicating that men from harsher environments (including mortality rates, life expectancies, and the impact of communicable diseases) prefer less feminine female faces (Marcinkowska et al. 2014). PentonVoak et al. (2004) found that Jamaican men preferred more masculine female faces to a greater extent than British men, presumably due to higher exposure to pathogens in Jamaica. However, Dixson et al. (2017) did not find support for the association between pathogen exposure and men's preference for female faces. Moreover, Pereira et al. (2020) using Brazilian subjects have recently reported that men prefer feminine - not masculine - female faces under environmental threat.

In addition to the effect of exposure to pathogens (i.e., pathogen prevalence in the environment), researchers have also investigated the relationship between individual differences in pathogen disgust and the preference for sexually dimorphic faces in men and women. For example, using the Three-Domain Disgust Scale (Tybur et al. 2009), it has been shown that higher disgust sensitivity in women is associated with preferences for masculinity in male faces (DeBruine et al. 2010b; Jones et al. 2013a); and men's higher pathogen disgust is correlated with higher preference for feminine female faces (Jones et al. 2013b; Lee et al. 2013). However, it should be noted that McIntosh et al. (2017) did not find an association between women's self-reported pathogen disgust and their preferences for facial masculinity in male faces.

One limitation in most of the previous research has been a lack of proper pathogen threat exposure. Some of the studies have used national-level historical or current pathogen prevalence, or national-level health indices (e.g., DeBruine et al. 2010a; Marcinkowska et al. 2019). Others have related individual differences in disgust sensitivity and preference for faces (e.g., DeBruine et al. 2010b), or have experimentally exposed participants to pathogenic stimuli (e.g., McIntosh et al. 2017). The COVID-19 pandemic provides the opportunity to investigate the association of pathogenic threat and men's and women's preferences for sexual dimorphism of faces in a real-world situation.

In this study, we examined women's preference for masculinity in men's faces, and men's preference for femininity in women's faces, in the U.S. and Iran during the COVID-19 pandemic (in March 2020). We also investigated preferences for sexual dimorphism in faces in relation to both fear of pathogens (by using the Perceived Vulnerability to Disease survey; Duncan, Schaller and Park 2009) and pathogen disgust (by using the Pathogen Disgust subscale from Three-domain Disgust Scale; Tybur et al. 2009). While some authors argue there is a distinction between fear of pathogens and pathogen disgust (Murray and Schaller 2016), others argue that they are functionally identical (Lieberman and Patrick 2014).

\section{Method}

\section{Participants}

Study participants were recruited from both the U.S. and Iran in March 2020. In the U.S., 473 heterosexual men (age: $M=35.31$; $S D=10.66$ ) and 341 heterosexual women (Age: $\mathrm{M}=39.33$; $\mathrm{SD}=12.70$ ) were recruited. Participants were asked 
if they were aware of an ongoing coronavirus outbreak that originated in Wuhan, China. Eight males and four women gave a negative answer and were dropped from the study. The final number of U.S. participants was 465 men and 337 women. Data for U.S. participants were collected through a Qualtrics survey distributed online through Amazon Mechanical Turk (MTurk). MTurk has previously been validated for online data collection for the behavioral sciences (Casler et al. 2013; Hauser and Schwarz 2016). In Iran, 112 women were recruited as study participants by distributing a Qualtrics survey on social media. Two individuals were dropped from the study for being non-heterosexual, resulting in a total of 110 women (Age: $\mathrm{M}=36.09, \mathrm{SD}=10.42$ ). Almost no men in Iran chose to participate in the Qualtrics survey.

\section{Stimuli}

The face stimuli were produced and used in previous studies by other researchers (Buckingham et al. 2006; DeBruine et al. 2010a, b; DeBruine and Jones 2017). The stimuli used for female participants were 20 pairs of photos of young adult male faces; for each pair, one photo was the original and the other was digitally altered to increase masculinity. The stimuli used for male participants were 20 pairs of photos of sameaged female faces; for each pair, one photo was the original and the other was digitally altered to increase femininity.

\section{Measures}

Three-domain Disgust Scale To measure individual differences in pathogen disgust, we used the pathogen disgust scale from Three Domains of Disgust Scale, which comprises 21 items measuring attitudes to performing or observing actions. The three domains of disgust are moral disgust (e.g., forging someone's signature on a legal document), sexual disgust (e.g., hearing two strangers having sex), and pathogen disgust (e.g., stepping on dog poop). We used a 7-point Likert scale with 0 indicating not at all disgusting and 6 indicating extremely disgusting (Tybur et al. 2009).

Perceived Vulnerability to Disease To measure individuals' chronic concerns about the transmission of infectious diseases, we used the 15-item Perceived Vulnerability to Disease self-report instrument (Duncan et al. 2009), which ranges from 1 (strongly disagree) to 7 (strongly agree), with higher values indicating higher perception of vulnerability to diseases.

Health Participants self-reported their subjective current health from extremely bad (1) to extremely good (7).

Political Orientation Participants from the U.S. were asked to describe their political views on a 7-point Likert scale ranging from 1 (extremely liberal) to 7 (extremely conservative). 
COVID-19 We asked the participants the following two questions about their attitude toward the COVID-19 pandemic. 'How concerned are you in general about the coronavirus outbreak?' and 'When you are in public, how concerned are you about contracting the coronavirus?' Participants answered these questions on a 7-point Likert scale, with 1 being very low, and 7 very high.

\section{Procedure}

After consenting to participate, individuals answered demographic questions (age, sex, sexual orientation, political orientation, education, and marital status). Male participants were presented with 20 pairs of female faces differing in femininity in a 2-alternative forced-choice design, and were asked to select the face that they preferred (femininized vs original) out of each pair. The pairs were presented in a random order. In a similar experimental design, female participants were presented with 20 pairs of male faces differing in masculinity and were asked to select the face they preferred (masculinized vs original). Women's preferences for male facial masculinity, and men's preference for female facial femininity were calculated as the ratio of the selected number of masculinized or femininized faces chosen divided by the total number trials. Finally, participants were asked to answer pathogen disgust, perceived vulnerability to disease surveys, and questions about their health condition, and their perception about the COVID-19 pandemic. The scores for pathogen disgust and vulnerability to disease scales were averaged.

\section{Results}

Table 1 shows the zero-order partial correlation results between the variables of interest for US women when political orientation was controlled for. Results for preference for masculinity in men's faces did not show any significant correlation with concerns about COVID-19 variables, perceived vulnerability to disease, pathogen disgust, and current

Table 1 Zero-Order Partial Correlations for All Variables for US Women (N=337) Controlling for Political Orientation

\begin{tabular}{|c|c|c|c|c|c|c|}
\hline Variable & 1 & 2 & 3 & 4 & 5 & 6 \\
\hline 1. Preference for Masculinity & - & & & & & \\
\hline 2. COVID-19 Outbreak Concern & -0.02 & - & & & & \\
\hline 3. COVID-19 Contracting Concern in Public & -0.04 & $0.83 * * *$ & - & & & \\
\hline 4. Perceived Vulnerability to Disease & -0.03 & $0.28 * * *$ & $0.35 * * *$ & - & & \\
\hline 5. Pathogen Disgust & -0.04 & $0.25 * * *$ & $0.28 * * *$ & $0.31 * * *$ & - & \\
\hline 6. Health & -0.01 & 0.01 & -0.04 & $-0.16^{* *}$ & 0.06 & - \\
\hline$M$ & 0.42 & 4.90 & 4.61 & 4.26 & 4.20 & 5.39 \\
\hline$S D$ & 0.17 & 1.72 & 1.82 & 0.82 & 1.12 & 1.21 \\
\hline
\end{tabular}


health condition. Similarly, data from the Iranian women showed no significant correlation between masculinity preference and any of the variables of interest (see Table 2). However, for both samples, concern about COVID-19 and contracting the disease was associated with perceived vulnerability to disease and pathogen disgust. Moreover, pathogen disgust was negatively related with health condition for both women samples.

Table 3 shows the zero-order partial correlation results between the variables of interest for US men while controlling for political orientation. Results show that preference for female feminine faces was negatively associated with concern for contracting COVID-19, and perceived vulnerability to disease; and positively associated with their health condition. No association was found between facial femininity preference and pathogen disgust. Furthermore, similar to the female participants, concern about the COVID-19 and its contraction was correlated with perceived vulnerability to disease and pathogen disgust (see Table S1 in supplementary materials for the association of perceived vulnerability subcomponents and other variables).

To further investigate the relationship between pathogen disgust, perceived vulnerability to disease, and men's preferences for feminine female faces, we ran a multiple linear regression with pathogen disgust and perceived vulnerability to disease as predictors, and preference for femininity as the dependent variable, while controlling for health and political orientation of the participants. Results of the regression model were significant, $F(4,459)=4.67, p=.001$, adjusted $R^{2}=.03$. Perceived vulnerability to disease negatively predicted preference for feminine female faces $(p=.003)$, while health was a positive predictor $(p=.044$; see Table 4 for details; see supplementary material Tables S2-S5 for the results of the stepwise selection of variables in the regression model). Note that there is no evidence of multicollinearity among predictors in the model. The mean variance inflation factor (VIF) was less than 1.07, and the largest VIF was less than 1.17.

A test of the difference between the two independent correlations involving US men and US women does not show a significant difference between concern about the COVID-19 pandemic and preference for facial sexual dimorphism $(z=0.98, p=0.33)$. Similarly, the sex difference is marginal for the association between perceived

Table 2 Zero-Order Pearson Correlations for All Variables for Iranian Women $(\mathrm{N}=110)$

\begin{tabular}{|c|c|c|c|c|c|c|}
\hline Variable & 1 & 2 & 3 & 4 & 5 & 6 \\
\hline 1. Preference for Masculinity & - & & & & & \\
\hline 2. COVID-19 Outbreak Concern & -0.15 & - & & & & \\
\hline 3. COVID-19 Contracting Concern in Public & -0.02 & $0.695 * * *$ & - & & & \\
\hline 4. Perceived Vulnerability to Disease & 0.048 & $0.237 *$ & $0.387 * * *$ & - & & \\
\hline 5. Pathogen Disgust & 0.103 & $0.216^{*}$ & $0.200^{*}$ & $0.293 * *$ & - & \\
\hline 6. Health & 0.05 & 0.015 & -0.035 & $-0.205^{*}$ & -0.01 & - \\
\hline$M$ & 0.34 & 5.2 & 4.91 & 4.16 & 4.46 & 5.84 \\
\hline$S D$ & 0.17 & 1.61 & 1.73 & 0.84 & 0.87 & 1.02 \\
\hline
\end{tabular}


Table 3 Zero-Order Partial Correlations for All Variables for US Men ( $=465)$ Controlling for Political Orientation

\begin{tabular}{|c|c|c|c|c|c|c|}
\hline Variable & 1 & 2 & 3 & 4 & 5 & 6 \\
\hline 1. Preference for Femininity & - & & & & & \\
\hline 2. COVID-19 Outbreak Concern & -0.08 & - & & & & \\
\hline 3. COVID-19 Contracting Concern in Public & $-0.11 *$ & $0.78 * * *$ & - & & & \\
\hline 4. Perceived Vulnerability to Disease & $-0.15 * *$ & $0.38 * * *$ & $0.45 * * *$ & - & & \\
\hline 5. Pathogen Disgust & -0.01 & $0.23 * * *$ & $0.23 * * *$ & $0.30^{* * *}$ & - & \\
\hline 6. Health & $0.12 * *$ & -0.05 & -0.07 & $-0.22 * * *$ & -0.02 & - \\
\hline$M$ & 0.56 & 4.60 & 4.34 & 3.98 & 3.74 & 5.33 \\
\hline$S D$ & 0.15 & 1.92 & 1.98 & 0.80 & 1.19 & 1.24 \\
\hline
\end{tabular}

vulnerability to disease and preference for facial sexual dimorphism $(z=1.69, p=0.09)$ and between health and preference for facial sexual dimorphism $(\mathrm{z}=1.82, p=0.07)$.

\section{Discussion}

In the current study we examined the association of an actual pathogenic threat specifically the COVID-19 pandemic - and preferences for sexually dimorphic faces. In particular, we studied women's preference for masculine male faces across Iran and U.S., and men's preference for feminine female faces in U.S. participants. We also examined their perception of COVID-19, their perceived vulnerability to disease, current health condition, and their pathogen disgust.

Results for female participants did not reveal any significant association between concern over COVID-19 outbreak or contracting the disease and women's preference for masculine male faces. These findings held both for those in the U.S. and Iran. Furthermore, in support of previous research (Lee et al. 2013; McIntosh et al. 2017), our results did not reveal any relationship between women's self-reported pathogen disgust and preference for masculine faces across our two samples of Iranian and U.S. women. Similarly, preference for male faces was not associated with perceived disease vulnerability and health condition in women. Collectively, our results for women's preference for male facial masculinity adds to the previous research questioning the

Table 4 Results for the multiple regression for men's preference for female feminine faces

\begin{tabular}{llllc}
\hline & Estimate & $S E$ & $t$ & $p$ \\
\hline Intercept & 0.61 & 0.05 & 11.3 & $<.001$ \\
Perceived Vulnerability to Disease & -0.03 & 0.01 & -2.97 & .003 \\
Pathogen Disgust & 0.01 & 0.01 & 1.14 & .255 \\
Political Orientation & -0.01 & 0.01 & -1.44 & .150 \\
Health & 0.02 & 0.01 & 2.02 & .044 \\
\hline
\end{tabular}


association between pathogen concern and preference for facial masculinity (Dixson et al. 2017; Lee et al. 2013; McIntosh et al. 2017; Scott et al. 2010).

Results for male participants showed a negative association between preference for feminine female faces and men's concern for contracting COVID-19 in public, showing that men with a greater concern of contracting the disease preferred less feminine female faces. This result dovetails with previous research showing men from harsher environments with higher mortality rates and communicable diseases prefer less feminine female faces (Marcinkowska et al. 2014; Penton-Voak et al. 2004). Accordingly, our results support the idea that men's mating preference under a pathogenic threat might shift from potentially fecund partners to cues of resource holding power (Marcinkowska et al. 2014). Similarly, our data on self-reported perceived vulnerability to disease and health condition support the association between COVID-19 threat and femininity preference, as those men with better health and lower perceived disease vulnerability preferred more feminine female faces.

However, contrary to previous research (Jones et al. 2013b; Lee et al. 2013), our results did not reveal any relationship between pathogen disgust and preference for feminine faces in men, suggesting that pathogen disgust and perceived disease vulnerability may not necessarily have the same influence on men's mate preferences. While some argue that behavioral immune system (Schaller 2006, 2011) and pathogen disgust (Tybur et al. 2009) are functionally identical (Lieberman and Patrick 2014), our results support those that argue for a distinction between these two systems (Murray and Schaller 2016), at least for men's preference of female facial femininity.

Furthermore, the present results showed that individuals who scored higher on perceived vulnerability to diseases were more concerned about the COVID-19 pandemic, and also with contracting the virus while in public; and they reported higher pathogen disgust. These positive associations were similar for both men and women (i.e., women from both Iran and the US). However, our results showed an association between self-report of current health and perceived disease vulnerability, but not with pathogen disgust, dovetailing with the distinction argument of perceived disease vulnerability and pathogen disgust (Murray and Schaller 2016).

Finally, it should be noted that the sex difference found in our results - a significant association between concern about the COVID-19 pandemic and preference for female faces by men, but a nonsignificant association for male faces by women - are not conclusive (Amrhein et al. 2019). Therefore, more research and evidence are warranted before a definitive statement can be made about the sex difference in sexual dimorphic preference in response to an actual pathogen stress such as COVID-19.

In summary, results of the current study show that concern about contracting COVID-19 predicts men's preference for female facial femininity, but not women's preference for male facial masculinity. By using an actual pathogenic threat, in contrast to previous research that employed surveys or stimuli to expose participants to pathogens (experimentally pathogen cuing by presenting facial stimuli immediately after pathogen cues), our results support previous findings that men's preference for female faces are shifted to less feminine faces under pathogenic threat, as higher femininity in women might be less adaptive (e.g., lower ability in competition for resources) in such conditions (Marcinkowska et al. 2014). Moreover, our results provide support for the distinction between the behavioral immune system and pathogen disgust (Murray and Schaller 2016) among male participants for femininity facial preferences. 
Supplementary Information The online version contains supplementary material available at https://doi.org/ 10.1007/s40750-020-00158-w.

Acknowledgements The authors would like to thank the Editor in Chief, Professor Dario Maestripieri, and two anonymous reviewers for their constructive comments on a previous version of this paper.

Funding This work was supported by a Killam Postdoctoral Research Fellowship awarded to FP, and grants to AK from the Natural Sciences and Engineering Research Council of Canada (2016-04319), and the Social Sciences and Humanities Research Council of Canada (435-2019-0749).

\section{Compliance with Ethical Standards}

All participants consented to taking part in the study. This research was approved by the Behavioural Research Ethics Committee of the University of British Columbia and was conducted in accordance with the Declaration of Helsinki as it pertains to research with human participants.

Conflict of Interest The authors declare that they have no conflict of interest.

\section{References}

Amrhein, V., Greenland, S., \& McShane, B. (2019). Scientists rise up against statistical significance. Nature, 567(7748), 305-307.

Barber, N. (1995). The evolutionary psychology of physical attractiveness: Sexual selection and human morphology. Ethology and Sociobiology, 16(5), 395-424.

Buckingham, G., DeBruine, L. M., Little, A. C., Welling, L. L., Conway, C. A., Tiddeman, B. P., \& Jones, B. C. (2006). Visual adaptation to masculine and feminine faces influences generalized preferences and perceptions of trustworthiness. Evolution and Human Behavior, 27(5), 381-389.

Casler, K., Bickel, L., \& Hackett, E. (2013). Separate but equal? A comparison of participants and data gathered via Amazon's MTurk, social media, and face-to-face behavioral testing. Computers in Human Behavior, 29(6), 2156-2160.

DeBruine, L. M., \& Jones, B. C. (2017). Young adult white faces with manipulated versions. figshare. https:// doi.org/10.6084/m9.figshare.4220517.

DeBruine, L. M., Jones, B. C., Crawford, J. R., Welling, L. L., \& Little, A. C. (2010). The health of a nation predicts their mate preferences: cross-cultural variation in women's preferences for masculinized male faces. Proceedings of the Royal Society B: Biological Sciences, 277(1692), 2405-2410.

DeBruine, L. M., Jones, B. C., Tybur, J. M., Lieberman, D., \& Griskevicius, V. (2010b). Women's preferences for masculinity in male faces are predicted by pathogen disgust, but not by moral or sexual disgust. Evolution and Human Behavior, 31(1), 69-74.

Dixson, B. J., Little, A. C., Dixson, H. G., \& Brooks, R. C. (2017). Do prevailing environmental factors influence human preferences for facial morphology? Behavioral Ecology, 28(5), 1217-1227.

Duncan, L. A., Schaller, M., \& Park, J. H. (2009). Perceived vulnerability to disease: Development and validation of a 15-item self-report instrument. Personality and Individual Differences, 47(6), 541-546.

Gangestad, S. W., \& Buss, D. M. (1993). Pathogen prevalence and human mate preferences. Ethology and Sociobiology, 14, 89-96.

Hamilton, W. D., \& Zuk, M. (1982). Heritable true fitness and bright birds: a role for parasites? Science, 218(4570), 384-387.

Hauser, D. J., \& Schwarz, N. (2016). Attentive Turkers: MTurk participants perform better on online attention checks than do subject pool participants. Behavior Research Methods, 48(1), 400-407.

Jones, B. C., Feinberg, D. R., Watkins, C. D., Fincher, C. L., Little, A. C., \& DeBruine, L. M. (2013a). Pathogen disgust predicts women's preferences for masculinity in men's voices, faces, and bodies. Behavioral Ecology, 24(2), 373-379. 
Jones, B. C., Fincher, C. L., Welling, L. L., Little, A. C., Feinberg, D. R., Watkins, C. D., \& DeBruine, L. M. (2013b). Salivary cortisol and pathogen disgust predict men's preferences for feminine shape cues in women's faces. Biological Psychology, 92(2), 233-240.

Lee, A. J., Dubbs, S. L., Kelly, A. J., von Hippel, W., Brooks, R. C., \& Zietsch, B. P. (2013). Human facial attributes, but not perceived intelligence, are used as cues of health and resource provision potential. Behavioral Ecology, 24(3), 779-787.

Lieberman, D., \& Patrick, C. (2014). Are the behavioral immune system and pathogen disgust identical? Evolutionary Behavioral Sciences, 8(4), 244.

Low, B. S. (1990). Marriage systems and pathogen stress in human societies. American Zoologist, 30(2), 325340 .

Marcinkowska, U. M., Kozlov, M. V., Cai, H., Contreras-Garduño, J., Dixson, B. J., Oana, G. A., ... Prasai, K. (2014). Cross-cultural variation in men's preference for sexual dimorphism in women's faces. Biology Letters, 10(4), 20130850.

Marcinkowska, U. M., Rantala, M. J., Lee, A. J., Kozlov, M. V., Aavik, T., Cai, H., .. Onyishi, I. E. (2019). Women's preferences for men's facial masculinity are strongest under favorable ecological conditions. Scientific Reports, 9(1), 1-10.

McIntosh, T. L., Lee, A. J., Sidari, M. J., Stower, R. E., Sherlock, J. M., \& Dixson, B. J. (2017). Microbes and masculinity: Does exposure to pathogenic cues alter women's preferences for male facial masculinity and beardedness? PLoS One, 12(6), e0178206.

Moore, F. R., Coetzee, V., Contreras-Garduño, J., DeBruine, L. M., Kleisner, K., Krams, I., ... Schaum, N. (2013). Cross-cultural variation in women's preferences for cues to sex-and stress-hormones in the male face. Biology Letters, 9(3), 20130050.

Murray, D. R., \& Schaller, M. (2016). The behavioral immune system: Implications for social cognition, social interaction, and social influence. In Advances in experimental social psychology (Vol. 53, pp. 75129). Cambridge: Academic.

Penton-Voak, I. S., Jacobson, A., \& Trivers, R. (2004). Populational differences in attractiveness judgements of male and female faces: Comparing British and Jamaican samples. Evolution and Human Behavior, 25(6), 355-370.

Pereira, K. J., David, V. F., Varella, M. A. C., \& Valentova, J. V. (2020). Environmental threat influences preferences for sexual dimorphism in male and female faces but not voices or dances. Evolution and Human Behavior, 41(4), 303-311.

Puts, D. A., Jones, B. C., \& DeBruine, L. M. (2012). Sexual selection on human faces and voices. Journal of Sex Research, 49(2-3), 227-243.

Rhodes, G., Chan, J., Zebrowitz, L. A., \& Simmons, L. W. (2003). Does sexual dimorphism in human faces signal health? Proceedings of the Royal Society of London. Series B: Biological Sciences, 270(suppl_1), S93-S95.

Rhodes, G., Simmons, L. W., \& Peters, M. (2005). Attractiveness and sexual behavior: Does attractiveness enhance mating success? Evolution and Human Behavior, 26(2), 186-201.

Schaller, M. (2006). Parasites, behavioral defenses, and the social psychological mechanisms through which cultures are evoked. Psychological Inquiry, 17(2), 96-101.

Schaller, M. (2011). The behavioural immune system and the psychology of human sociality. Philosophical Transactions of the Royal Society B: Biological Sciences, 366(1583), 3418-3426.

Scott, I. M., Pound, N., Stephen, I. D., Clark, A. P., \& Penton-Voak, I. S. (2010). Does masculinity matter? The contribution of masculine face shape to male attractiveness in humans. PLoS One, 5(10), e13585.

Thornhill, R., \& Gangestad, S. W. (1993). Human facial beauty. Human Nature, 4(3), 237-269.

Thornhill, R., \& Gangestad, S. W. (1999). Facial attractiveness. Trends in Cognitive Sciences, 3(12), 452-460.

Tybur, J. M., \& Gangestad, S. W. (2011). Mate preferences and infectious disease: Theoretical considerations and evidence in humans. Philosophical Transactions of the Royal Society B: Biological Sciences, 366(1583), 3375-3388.

Tybur, J. M., Lieberman, D., \& Griskevicius, V. (2009). Microbes, mating, and morality: individual differences in three functional domains of disgust. Journal of Personality and Social Psychology, 97(1), 103-122.

Publisher's Note Springer Nature remains neutral with regard to jurisdictional claims in published maps and institutional affiliations. 


\section{Affiliations}

\section{Farid Pazhoohi ${ }^{1} \cdot$ Sepide Pazhouhi ${ }^{2} \cdot$ Alan Kingstone $^{1}$}

1 Department of Psychology, University of British Columbia, 2136 West Mall, Vancouver, British Columbia V6T 1Z4, Canada

2 Department of Psychology, Shahid Beheshti University, Tehran, Iran 